Bulletin of Pharmaceutical Sciences
Assiut University

REVIEW ARTICLE

\title{
CHITOSAN MICROSPHERES AS POTENTIAL CARRIERS FOR COLON TARGETING
}

\author{
Hytham H. Gadalla ${ }^{*}$ A. M. El-Sayed, Fergany A. M., I. El-Gibaly and Ghareb M. Soliman \\ Department of Pharmaceutics, Faculty of Pharmacy, Assiut University, Assiut 71526, Egypt
}

\begin{abstract}
Chitosan microspheres have been in the focus of increasing interest as polymeric drug carriers due to their appealing properties such as biocompatibility, biodegradability, low toxicity, mucoadhesion and relatively low cost of production. Gel formation can be obtained by interactions of chitosan with low molecular weight counter-ions such as polyphosphates. However, one drawback of using this natural polysaccharide for oral controlled release dosage forms is its fast dissolution rate in the stomach. Since chitosan is positively charged at low pH values (below its pKa value), it spontaneously associates with polyanions to form polyelectrolyte complexes (PEC). These PEC exhibit favorable physicochemical properties with preservation of chitosan's biocompatible characteristics. These complexes are therefore good candidates for the design of colon-targeted dosage forms. Various techniques are used for preparing chitosan microspheres which have been reviewed. This review also includes factors that affect the release characteristics of drugs from chitosan microspheres.
\end{abstract}

\section{INTRODUCTION}

Colon-specific drug delivery systems have gained increased interest in the last decades due to the well-recognized importance of this region of the GIT both for local and systemic administration of medicinal agents. Much interest has been given in directing drugs and dosage forms to affect primary drug release in the colon ${ }^{1}$. Systems which can deliver drugs specifically to the colon without losing them in the upper parts of the GIT are referred to as colon-specific drug delivery systems ${ }^{2}$.

\section{Rationales for colon targeting}

The rationales for development of orally administered colonic drug delivery systems include: (a) The opportunity to reduce adverse effects in the treatment of local colonic disorders; (b) Elucidation of the mode of action of some non-steroidal anti-inflammatory drugs (NSAIDs) such as sulindac ${ }^{3}$; (c) The recognition that the colon is capable of absorbing drugs efficiently; (d) Accumulated evidence that drug absorption enhancement works better in the colon than in the small intestine $^{4}$; (e) The anticipation that protein drugs can be absorbed better from the large bowel owing to the reduced proteolytic activity in this organ $^{5}$ and (f) The unique metabolic activity of the colon that makes it an attractive organ for the design of drug delivery systems ${ }^{6}$.

\section{Approaches utilized to achieve colonic targeting \\ Various approaches have been utilized for} the development of colon specific drug delivery systems. They can be categorized as: (a) Prodrug approach ${ }^{7}$; (b) Pressure-based systems $^{8 \& 9}$; (c) The temporal control of delivery $^{10}$; (d) $\mathrm{pH}^{-b a s e d}$ systems ${ }^{11-13}$ and (e) Enzyme-based systems ${ }^{14}$. Among these approaches, the one in which the drug release is triggered by the colonic microflora seems to be the most specific due to its unique selectivity ${ }^{15 \& 16}$.

The universal polysaccharide systems which suffer hydrolysis of their glycosidic bonds in the colon, appear to be the most promising because of their practicality and exploitation of the most distinctive property of 
the colon, its abundant microflora ${ }^{17}$. Colonic bacterial enzymes are capable of degrading these natural polymers in the colon, despite being not affected either in the stomach or in the small intestine ${ }^{18}$.

\section{Microspheres as multiple-unit dosage forms}

Polymeric microspheres have emerged as a safe and efficient oral drug delivery systems by virtue of their interesting properties, such as their smaller size and larger surface area that improve drug absorption as compared to larger carriers $^{19}$. In addition, these matrix-type microspheres, in which the drug is dispersed or dissolved, showed a potential to enhance the drug stability and improve the oral bioavailability of water-insoluble or hydrophobic drugs such as nifedipine, curcumin,.... etc. ${ }^{20 \& 21}$.

These multiparticulate systems were shown to quickly spread out on their arrival to the colon with a sharp increase in the surface area exposed to bacterial breakdown which produces a rapid drug release and thereby improve drug absorption ${ }^{22}$. Polysaccharidebased microspheres have an additional unique advantage which is their ability to adhere to mucus layers of the colon.

\section{Chitosan (CS)}

Chitosan is a cationic polysaccharide obtained by the alkaline N-deacetylation of chitin, the main component of the protective shells of crustaceans ${ }^{23}$. It is the second most abundant natural polymer on Earth next to cellulose $^{24}$. It is a linear co-polymer polysaccharide consisting of $\beta$ (1-4)-linked 2amino-2-deoxy-D-glucose (D-glucosamine) and 2-acetamido-2-deoxy-D-glucose (N-acetyl-Dglucosamine units ${ }^{25}$ as depicted in figure 1 .
Chitosan is a weak base which is insoluble in water and organic solvents, however, it is soluble in dilute aqueous acidic solution $(\mathrm{pH}<$ 6.5), which can convert the glucosamine units into a soluble form $\mathrm{R}-\mathrm{NH}^{+}{ }^{23}$. It represent a series of polymers of different degrees of deacetylation (DD), expressed as the percentage of primary amino groups present in the polymer backbone and the average molecular weights $(\mathrm{Mw})$. The $\mathrm{DD}$ for commercial-grade chitosan ranges between $70 \%$ and $95 \%$, and the $\mathrm{Mw}$ between 10 and $1000 \mathrm{kDa}$.. It has a $\mathrm{pKa}$ around 6.3. The physico-chemical properties and biodegradability of chitosan are both highly dependent on the relative proportions of $\mathrm{N}$-acetyl-D-glucosamine and D-glucosamine residues ${ }^{25}$.

Chitosan has been extensively investigated as an adjuvant in many pharmaceutical applications such as (a) vehicle for directly compressed tablets $^{26}$, (b) disintegrant ${ }^{27}$, (c) binder $^{28}$, (d) granulating agent in tablet manufacture $^{29}$, (e) co-grinding diluent for improving the dissolution characteristics and bioavailability of poorly water-soluble drugs ${ }^{30}$ as well as (f) drug carrier for sustained release preparations $^{31-33}$.

Additionally, chitosan combine many interesting features, such as safety, inertness, non-toxicity, biocompatibility, biodegradability as well as mucoadhesion. Chemically, chitosan has one primary amino and two free hydroxyl groups in each building block and due to the availability of this amino group, chitosan carries positive charges, at $\mathrm{pH}$ values $\leq 6.5$, that enable it to react with a variety of negatively charged polymers and surfaces ${ }^{34}$.

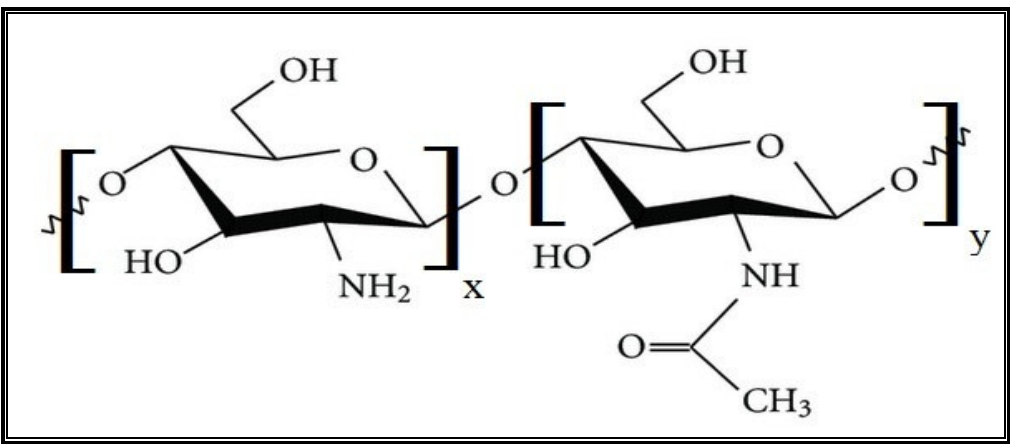

Fig. 1: Chemical structure of chitosan. The indices $\mathrm{x}$ and $\mathrm{y}$ represent the mole fractions of $\mathrm{D}$ glucosamine and $\mathrm{N}$-acetyl-D-glucosamine moieties, respectively 


\section{Chitosan microspheres}

Chitosan microspheres have been widely studied as a matrix for the controlled release of drugs $^{35-39}$. However, these microspheres have shown limited strength along with very fast drug release in the stomach due to the high solubility of chitosan in acidic media ${ }^{40-42}$. Despite this fact, the use of chitosan for colonic targeting offers a great advantage by virtue of its insolubility at $\mathrm{pH}$ values above 6.5 that prevail in the jejunum and ileum parts of the small intestine while it gets soluble again at $\mathrm{pH}$ of the $\operatorname{colon}^{43}$. Thus chitosan has to be combined with another polymer, usually polyanion, to prevent premature drug release in the stomach and ideally release it in the colon ${ }^{43}$.

\section{Chitosan polyelectrolyte complexes}

Polyelectrolyte complexes (PECs) are biocompatible hydrogel networks formed by interaction between macromolecules, bearing a relatively large number of oppositely charged functional groups, in an aqueous medium ${ }^{44}$. Mixing of these polyelectrolytes in solution results in their spontaneous self assembly due to the promotion of strong, but reversible, electrostatic linkages between them ${ }^{45}$.

PEC are, generally, characterized by having hydrophilic micro-structure with a high water content and electrical charge density ${ }^{46}$. In addition, these PEC exhibit a pH-dependent swelling behavior which represent an interesting property allowing the controlledrelease of different entrapped substance such as, medicinal agents, enzymes or bacteria until it reaches the colon ${ }^{47 \& 48}$. This $\mathrm{pH}$-sensitive swelling behavior could be explained in light of their higher degree of swelling at $\mathrm{pH}$ between the $\mathrm{pKa}$ values of the functional groups involved in the PEC formation, where both become ionized ${ }^{49}$.

Over the last years, PEC between chitosan and many polyanions have been prepared and investigated as drug carriers such as, chitosanalginate $\mathrm{PEC}^{50 \& 51}$, chitosan-pectin $\mathrm{PEC}^{52-54}$, chitosan-NaCMC PEC ${ }^{55 \& 56}$ chitosancarrageenan $\mathrm{PEC}^{57 \& 58}$, chitosan-xanthan gum $\mathrm{PEC}^{59 \& 60}$, chitosan-hyaluronic acid $\mathrm{PEC}^{61 \& 62}$, chitosan-kondagogu gum $\mathrm{PEC}^{63}$ and chitosangelatin $\mathrm{PEC}^{64 \& 65}$.

In particular, PECs formed between pectin and chitosan are considered as promising candidates for colon-targeted delivery of therapeutically-active moieties because of its physiological inertness and relatively higher resistance to enzymatic degradation ${ }^{66 \& 67}$. Microspheres based on this complex were proven to have better protective effect against immature drug release in the stomach as the interaction between pectin or and chitosan is more favored at low $\mathrm{pH}$ values ${ }^{68}$.

\section{Preparation of chitosan PECs}

The preparation of such PECs is a mild and reversible process requiring only the reacting species. It requires no auxiliary molecules as initiators or catalysts, no additional purification steps, and is almost done in aqueous medium ${ }^{44}$. Therefore, this electrostatic interaction was found to be superior to the chemical (covalent) crosslinking reaction, with respect to the safety and avoidance of organic solvents and chemical cross-linkers thereby, reducing toxicity and undesirable side-effects ${ }^{69}$.

Two methods were reported for the formation of chitosan PEC. The single step method is a simple and efficient one in which, an aqueous solution of the polyanion is added dropwise into the crosslinking medium containing chitosan ${ }^{51}$. Alternatively, a twostage method is available which involves coating of the preformed Ca-pectinate or Caalginate beads with an external membrane of chitosan $^{70}$.

\section{Drugs formulated as chitosan microspheres for colonic targeting}

Various categories of drugs could be targeted to the colon, including drugs which are unabsorbed in the upper GIT or those required for treatment of local colonic pathologies. Moreover, the colonic delivery is also beneficial for systemic absorption of some drugs. Chitosan-based microspheres were extensively investigated for various classes of drugs, such as anticancer drugs including Fluorouracil $^{71}, \quad$ Cisplatin $^{72}$, Mitoxantrone ${ }^{73}$, Methotrexate $^{74}$ and Taxol ${ }^{75}$; anti-inflammatory drugs including Indomethacin ${ }^{76}$, Diclofenac sodium $^{77}$, Prednisolone ${ }^{78}$, Ketoprofen ${ }^{79}$, Piroxicam $^{80}$ and Sulfasalazine ${ }^{81}$; cardiovascular drugs including Diltiazem ${ }^{82}$, Nifedipine ${ }^{83}$, Propranolol $^{84}$ and Isosorbide mononitrate ${ }^{85}$; antibiotics including Amoxycillin ${ }^{86}$, 
Ampicillin $^{87}$, tetracycline ${ }^{16}$ and sulfathiazole ${ }^{88}$ in addition to protein hormones including Insulin $^{89}$ and Growth hormone ${ }^{90}, \ldots$ etc.

\section{Factors affecting drug release behavior from chitosan microspheres}

Many parameters can influence the

drug release behavior from chitosan microspheres. These include concentration and molecular weight of the chitosan, the type and concentration of crosslinking agent, variables like stirring speed, type of oil, additives, nature of the crosslinking process used, drug: chitosan ratio,... etc. The most important factors can be summarized as following:

\section{Effect of cross-linking degree}

The crosslinking density appears to be the most crucial parameter affecting the release of drugs from chitosan microspheres. Jameela et $a l .{ }^{91}$ have revealed that highly cross-linked microspheres released only $35 \%$ of the progesterone in 40 days as compared to $70 \%$ release from microspheres cross-linked lightly. Also, Ko et $a l .{ }^{92}$ prepared felodipine-loaded chitosan microparticles with tripolyphosphate (TPP) by ionic crosslinking. The release of drug from TPP-chitosan microparticles was markedly reduced upon increasing the crosslinking time as well as TPP concentration. Mitoxantrone release from chitosan microspheres was also controlled by the extent of crosslinking. The crosslinking was carried out using glutaraldehyde-saturated toluene ${ }^{73}$. Only about $25 \%$ of the drug was released over 36 days from highly crosslinked microspheres. Moreover, Kumar et al. ${ }^{93}$ encapsulated curcumin in bovine serum albumin and chitosan microspheres to form a depot forming drug delivery system. In-vitro release studies indicated a biphasic drug release pattern, characterized by burst-effect followed by a slow release which was highly dependent on the cross-linking density.

\section{Effect of chitosan concentration}

Several authors have reported that the rate of drug release from chitosan microspheres was reduced upon increasing chitosan concentration. Nishioka et al. ${ }^{94}$ have found that the release rates of cisplatin from such microspheres decreased significantly upon increasing chitosan concentration. Similar finding was reported later by Ko et al. ${ }^{92}$ for chitosan microspheres loaded with felodipine. These results were consistent with those obtained by Aiedehe et al. ${ }^{95}$ who prepared chitosan-based biodegradable system for oral delivery of insulin. The release rate of insulin could be increased considerably by decreasing chitosan content in the preparative solution.

\section{Effect of molecular weight of chitosan}

Generally, drug release studies from chitosan microspheres have shown that the drug release rates decreases with an increase in molecular weight (MW) of chitosan. Shiraishi et $a l .{ }^{96}$ and Al-Helw et al. ${ }^{97}$ have reported that the release of indomethacin and phenobarbitone from crosslinked chitosan microspheres was slower from microspheres prepared with high MW chitosan as compared to medium and low MW chitosan microspheres, respectively. In another study, Polk et al. ${ }^{69}$ reported that chitosan MW is a key variable in the release of albumin from chitosan microspheres. Decreasing the MW increased the release of albumin (from 37\% after $4 \mathrm{~h}$ with high MW chitosan to $77 \%$ release with low MW chitosan). Capsules produced with a combination of high and low MW chitosan gave the best results for reducing leaching of albumin in the first $4 \mathrm{~h}$ and increasing elution in the subsequent hours. However, Genta et al. ${ }^{79}$ reported that the fastest ketoprofen release profile from chitosan microspheres was obtained with medium MW chitosan. This was attributed to the swelling behavior of chitosan microspheres. An increase in MW of chitosan leads to increase in viscosity of the gel layer, which influences the diffusion of the drug as well as erosion of the microspheres.

\section{Effect of drug content in the microspheres}

The effect of drug content on the drug release properties from chitosan microspheres was controversial and seems to be related to the nature of loaded drugs. Bayomi et al. ${ }^{82}$ have shown that the release of the drug from microspheres increased with increasing drug content in the microspheres. Furthermore, Akbuga and Durmaz ${ }^{98}$ reported that the release of furosemide from chitosan microspheres followed the Higuchi-matrix kinetic model i.e., increased drug release upon increasing the 
amount of furosamide incorporated. However, contradictory results have been reported by Bodmeier et al. ${ }^{99}$ who reported that the release of sulfadiazine decreased with increasing the drug content in microspheres. This was explained by virtue of the water-insoluble nature of the encapsulated drug (sulfadiazine).

\section{Conclusion}

Ionic crosslinking with counter-ions or polyanions is an extremely simple and mild method for preparing chitosan microspheres. Moreover, ionically cross-linked chitosan hydrogels are often biocompatible and welltolerated with numerous potential medical and pharmaceutical applications. These hydrogels offer better safety profiles and opportunities as drug delivery systems when compared to covalently cross-linked hydrogels. They can be used for controlled release of medicinal agents, not only in acidic but also in basic media and as thermo-gelling systems. However, the main disadvantages accompanying the use of these polymeric systems as drug carriers are the possible lack of mechanical stability and the risk of rapid dissolution of the system, especially at low $\mathrm{pH}$ values, due to a highly $\mathrm{pH}$-sensitive swelling behavior.

\section{REFERENCES}

1- S. Singh, "Recent advancement in floating drug delivery system", Int. J. Pharm. Sci., 2, (2013).

2- S. Tamizharasi, "Conventional and novel approaches for colon specific drug delivery: A Review", Ind. J. Pharm., (2011).

3- C. S. Williams, A. P. Goldman, H. Sheng, J. D. Morrow and R. N. DuBois, "Sulindac sulfide, but not sulindac sulfone, inhibits colorectal cancer growth", Neoplasia., 1, 170-6 (1999)

4- G. Fetih, S. Lindberg, K. Itoh, N. Okada, T. Fujita, F. Habib, P. Artersson, M. Attia and A. Yamamoto, "Improvement of absorption enhancing effects of $n$ dodecyl- $\beta$-d-maltopyranoside by its colonspecific delivery using chitosan capsules", Int. J. Pharm., 293, 127-35 (2005).

5- S. M. Haupt and A. Rubinstein, "The colon as a possible target for orally administered peptide and protein drugs", Crit. Rev. Ther. Drug, 19, (2002).

6- R. R. Scheline, "Metabolism of foreign compounds by gastrointestinal microorganisms", Pharmacol. Rev., 25, 451 (1973).

7- S. Riley and L. Turnberg, "Sulphasalazine and the aminosalicylates in the treatment of inflammatory bowel disease", QJM., 75, 551-62 (1990).

8- Y. I. Jeong, T. Ohno, Z. Hu, Y. Yoshikawa, N. Shibata, S. Nagata and K. Takada, "Evaluation of an intestinal pressure-controlled colon delivery capsules prepared by a dipping method", J. Controlled Release, 71, 175-82 (2001).

9- J. Aurora, N. Talwar and V. Pathak, "Colonic drug delivery challenges and opportunities-an overview", Eur. Gastroenterol. Rev., 1, 1-4 (2006).

10- K. Steed, G. Hooper, N. Monti, M. Strolin Benedetti, G. Fornasini and I. Wilding, "The use of pharmacoscintigraphy to focus the development strategy for a novel 5-ASA colon targeting system ("TIME CLOCK< $<$ sup $>$ (®)/sup> $>$ system)", $\quad J$. Controlled Release, 49, 115-22 (1997).

11- S. Klein, J. Stein and J. Dressman, "Site-specific delivery of anti-inflammatory drugs in the gastrointestinal tract: An in-vitro release model", J. Pharm. Pharmacol., 57, 70919 (2005).

12- V. C. Ibekwe, H. M. Fadda, G. E. Parsons and A. W. Basit, "A comparative in-vitro assessment of the drug release performance of $\mathrm{pH}$-responsive polymers for ileo-colonic delivery", Int. J. Pharm., 308, 52-60 (2006).

13- V. C. Ibekwe, F. Liu, H. M. Fadda, M. K. Khela, D. F. Evans, G. E. Parsons and A. W. Basit, "An investigation into the invivo performance variability of $\mathrm{pH}$ responsive polymers for ileo-colonic drug delivery using gamma scintigraphy in humans", J. Pharm. Sci., 95, 2760-6 (2006).

14- M. M. Xi, S. Q. Zhang, X. Y. Wang, K. Q. Fang and Y. Gu, "Study on the characteristics of pectin-ketoprofen for colon targeting in rats", Int. J. Pharm., 298, 91-7 (2005). 
15- L. Yang, J. S. Chu and J. A. Fix, "Colonspecific drug delivery: New approaches and in-vitro/in-vivo evaluation", ibid., 235, 1-15 (2002).

16- R. Hejazi and M. Amiji, "Chitosan-based gastrointestinal delivery systems", $\boldsymbol{J}$. Controlled Release, 89, 151-65 (2003).

17- A. W. Basit, "Advances in colonic drug delivery", Drugs, 65, 1991-2007 (2005).

18- Y. V. R. Prasad, Y. S. R. Krishnaiah and S. Satyanarayana, "In-vitro evaluation of guar gum as a carrier for colon-specific drug delivery", J. Controlled Release, 51, 281-7 (1998).

19- A. Des. Rieux, V. Fievez, M. Garinot, YJ. Schneider and V. Préat, "Nanoparticles as potential oral delivery systems of proteins and vaccines: A mechanistic approach", ibid., 116, 1-27 (2006).

20- J. Huang, R. J. Wigent, C. M. Bentzley and J. B. Schwartz, "Nifedipine solid dispersion in microparticles of ammonio methacrylate copolymer and ethylcellulose binary blend for controlled drug delivery: Effect of drug loading on release kinetics", Int. J. Pharm., 319, 4454 (2006).

21- S. Wan, Y. Sun, L. Sun and F. Tan, "Chitosan microparticles for oral bioavailability improvement of the hydrophobic drug curcumin", Pharmazie, 67, 525-8 (2012).

22- M. Rodríguez, J. L. Vila-Jato and D. Torres, "Design of a new multiparticulate system for potential site-specific and controlled drug delivery to the colonic region", J. Controlled Release, 55, 67-77 (1998).

23- V. R. Sinha, A. K. Singla, S. Wadhawan, R. Kaushik, R. Kumria, K. Bansal and S. Dhawan, "Chitosan microspheres as a potential carrier for drugs", Int. J. Pharm., 274, 1-33 (2004).

24- R. GAF, "Chitin Chemistry", MacMillan Press Ltd., Houndmills, 1992.

25- M. George and T. E. Abraham, "Polyionic hydrocolloids for the intestinal delivery of protein drugs: Alginate and chitosan - a review", J. Controlled Release, 114, 1-14 (2006).

26- L. Ilium, "Chitosan and its use as a pharmaceutical excipient", Pharm. Res., 15, 1326-31 (1998).
27- A. G. Nigalaye, P. Adusumilli and S. Bolton, "Investigation of prolonged drug release from matrix formulations of chitosan", Drug Dev. Ind. Pharm., 16, 449-67 (1990).

28- S. M. Upadrashta, P. R. Katikaneni and N. O. Nuessle, "Chitosan as a tablet binder", ibid., 18, 1701-8 (1992).

29- R. Ilango, S. Kavimani, J. Premila, D. Nair and B. Jayakar, "Studies on tablets of sulphamethoxazole using chitosan", Indian J. Pharm. Sci., 59, 220 (1997).

30- S. Shiraishi, M. Arahira, T. Imai and M. Otagiri, "Enhancement of dissolution rates of several drugs by low-molecular chitosan and alginate", Chem. Pharm. Bull., 38, 185-7 (1990).

31- Y. Kawashima, T. Handa, A. Kasai, H. Takenaka, S. Lin and Y. Ando, "Novel method for the preparation of controlled-release theophylline granules coated with a polyelectrolyte complex of sodium polyphosphate-chitosan", $\boldsymbol{J}$. Pharm. Sci., 74, 264-8 (1985).

32- J. Akbuğa, "The effect of the physicochemical properties of a drug on its release from chitosonium malate matrix tablets", Int. J. Pharm., 100, 257-61 (1993).

33- J. Kristl, J. Šmid-Korbar, E. Štruc, M. Schara and H. Rupprecht, "Hydrocolloids and gels of chitosan as drug carriers", ibid., 99, 13-9 (1993).

34- H. Fukuda, "Polyelectrolyte complexes of chitosan with sodium carboxymethylcellulose", Bull. Chem. Soc. Jpn., 53, 837-40 (1980).

35- A. Ganza-González, S. Anguiano-Igea, F. J. Otero-Espinar and J. Blanco Méndez, "Chitosan and chondroitin microspheres for oral-administration controlled release of metoclopramide", Eur. J. Pharm. Biopharm., 48, 149-55 (1999).

36- A. K. Anal, W. F. Stevens and C. Remuñán-López, "Ionotropic cross-linked chitosan microspheres for controlled release of ampicillin", Int. J. Pharm., 312, 166-73 (2006).

37- K. C. Gupta and F. H. Jabrail, "Glutaraldehyde cross-linked chitosan microspheres for controlled release of centchroman", Carbhydr. Res., 342, 2244-52 (2007). 
38- R. Harris, I. Paños, N. Acosta and A. Heras, "Preparation and characterization of chitosan microspheres for controlled release of tramadol", J. Controlled Release, 132, e76-e7 (2008).

39- A. G. S. Prado, A. L. F. Santos, A. R. Nunes, G. W. Tavares and C. M. de Almeida, "Designed formulation based on $\alpha$-tocopherol anchored on chitosan microspheres for $\mathrm{pH}$-controlled gastrointestinal controlled release", Colloids Surf. B., 96, 8-13 (2012).

40- T. Chandy and C. P. Sharma, "Chitosan-as a biomaterial", Artif. Cell Blood Sub., 18, 1-24 (1990).

41- M. V. Risbud, A. A. Hardikar, S. V. Bhat and R. R. Bhonde, "pH-sensitive freezedried chitosan-polyvinyl pyrrolidone hydrogels as controlled release system for antibiotic delivery", J. Controlled Release, 68, 23-30 (2000),

42- M. Sivakumar, I. Manjubala and K. Panduranga Rao, "Preparation, characterization and in-vitro release of gentamicin from coralline hydroxyapatitechitosan composite microspheres", Carbohydr. Polym., 49, 281-8 (2002).

43- S. Wittaya-areekul, J. Kruenate and C. Prahsarn, "Preparation and in-vitro evaluation of mucoadhesive properties of alginate/chitosan microparticles containing prednisolone", Int. J. Pharm., 312, 113-8 (2006).

44- J. Berger, M. Reist, J. M. Mayer, O. Felt and R. Gurny, "Structure and interactions in chitosan hydrogels formed by complexation or aggregation for biomedical applications", Eur. J. Pharm. Biopharm., 57, 35-52 (2004).

45- J. H. Hamman, "Chitosan based polyelectrolyte complexes as potential carrier materials in drug delivery systems", Mar. Drugs, 8, 1305-22 (2010).

46- T. Takahashi, K. Takayama, Y. Machida and T. Nagai, "Characteristics of polyion complexes of chitosan with sodium alginate and sodium polyacrylate", Int. J. Pharm., 61, 35-41 (1990).

47- C-H Chu, T. Sakiyama and T. Yano, "pHsensitive swelling of a polyelectrolyte complex gel prepared from xanthan and chitosan", Biosci. Biotechnol. Biochem., 59, 717-9 (1995).
48- F. Chellat, M. Tabrizian, S. Dumitriu, E. Chornet, P. Magny, C. H. Rivard and L. H. Yahia, "In-vitro and in-vivo biocompatibility of chitosan-xanthan polyionic complex", J. Biomed. Mater. Res., A. 51, 107-16 (2000).

49- A. R. Fajardo, J. F. Piai, A. F. Rubira and E. C. Muniz, "Time-and pH-dependent self-rearrangement of a swollen polymer network based on polyelectrolytes complexes of chitosan/chondroitin sulfate", Carbohydr. Polym., 80, 934-43 (2010).

50- X. Li, H. Xie, J. Lin, W. Xie and X. Ma, "Characterization and biodegradation of chitosan-alginate polyelectrolyte complexes", Polym. Degrad. Stabil., 94, 1-6 (2009).

51- H. V. Sæther, H. K. Holme, G. Maurstad, O. Smidsrød and B. T. Stokke, "Polyelectrolyte complex formation using alginate and chitosan", Carbohydr. Polym., 74, 813-21 (2008).

52- P. Bernabé, C. Peniche and W. ArgüellesMonal, "Swelling behavior of chitosan/pectin polyelectrolyte complex membranes. Effect of thermal crosslinking", Polym. Bull., 55, 367-75 (2005).

53- F. Bigucci, B. Luppi, T. Cerchiara, M. Sorrenti, G. Bettinetti, L. Rodriguez and V. Zecchi, "Chitosan/pectin polyelectrolyte complexes: Selection of suitable preparative conditions for colonspecific delivery of vancomycin", Eur. J. Pharm. Sci., 35, 435-41 (2008).

54- S. Pandey, A. Mishra, P. Raval, H. Patel, A. Gupta and D. Shah, "Chitosan-pectin polyelectrolyte complex as a carrier for colon targeted drug delivery", J. Young Pharm., 5, 160-6 (2013).

55- J. Liuyun, L. Yubao and X. Chengdong, "A novel composite membrane of chitosan-carboxymethyl cellulose polyelectrolyte complex membrane filled with nano-hydroxyapatite I. Preparation and properties", J. Mater. Sci.-Mater., M. 20, 1645-52 (2009).

56- C. Rosca, M. I. Popa, G. Lisa and G. C. Chitanu, "Interaction of chitosan with natural or synthetic anionic polyelectrolytes. 1. The chitosan-carboxymethylcellulose complex", Carbohydr. Polym., 62, 35-41 (2005). 
57- E. Shumilina and Y. A. Shchipunov, "Chitosan-carrageenan gels", Colloid J., 64, 372-8 (2002).

58- A. V. Briones and T. Sato, "Encapsulation of glucose oxidase (GOD) in polyelectrolyte complexes of chitosancarrageenan", React. Funct. Polym., 70, 19-27 (2010).

59- D. Magnin, J. Lefebvre, E. Chornet and S. Dumitriu, "Physicochemical and structural characterization of a polyionic matrix of interest in biotechnology, in the pharmaceutical and biomedical fields" Carbohydr. Polym., 55, 437-53 (2004).

60- S. Argin-Soysal, P. Kofinas and Y. M. Lo, "Effect of complexation conditions on xanthan-chitosan polyelectrolyte complex gels", Food Hydrocoll., 23, 202-9 (2009).

61- J. Y. Fang, J. P. Chen, Y. L. Leu and J. W. $\mathrm{Hu}, \quad$ "Temperature-sensitive hydrogels composed of chitosan and hyaluronic acid as injectable carriers for drug delivery", Eur. J. Pharm. Biopharm., 68, 626-36 (2008).

62- F. Oyarzun-Ampuero, J. Brea, M. Loza, D. Torres and M. Alonso, "Chitosanhyaluronic acid nanoparticles loaded with heparin for the treatment of asthma", Int. J. Pharm., 381, 122-9 (2009).

63- V. Naidu, K. Madhusudhana, R. Sashidhar, S. Ramakrishna, R. K. Khar, F. J. Ahmed and P. V. Diwan, "Polyelectrolyte complexes of gum kondagogu and chitosan, as diclofenac carriers", Carbohydr. Polym., 76, 464-71 (2009).

64- Y. Yin, Z. Li, Y. Sun and K. Yao, "A preliminary study on chitosan/gelatin polyelectrolyte complex formation", $\boldsymbol{J}$. Mater. Sci., 40, 4649-52 (2005).

65- N. H. Foda, H. M. El-laithy and M. I. Tadros, "Implantable biodegradable sponges: Effect of interpolymer complex formation of chitosan with gelatin on the release behavior of tramadol hydrochloride", Drug Dev. Ind. Pharm., 33, 7-17 (2007).

66- M. Hiorth, T. Versland, J. Heikkilä, I. Tho and S. A. Sande, "Immersion coating of pellets with calcium pectinate and chitosan", Int. J. Pharm., 308, 25-32 (2006).
67- N. Mennini, S. Furlanetto, F. Maestrelli, S. Pinzauti and P. Mura, "Response surface methodology in the optimization of chitosan-Ca pectinate bead formulations", Eur. J. Pharm. Sci., 35, 318-25 (2008).

68- O. Munjeri, J. H. Collett and J. T. Fell, "Hydrogel beads based on amidated pectins for colon-specific drug delivery: The role of chitosan in modifying drug release", J. Controlled Release, 46, 273-8 (1997).

69- A. Polk, B. Amsden, K. De Yao, T. Peng and M. Goosen, "Controlled release of albumin from chitosan-alginate microcapsules", J. Pharm. Sci., 83, 17885 (1994).

70- J. R. R. de Souza, J. I. X. de Carvalho, M. T. S. Trevisan, R. C. M. de Paula, N. M. P. S. Ricardo and J. P. A. Feitosa, "Chitosan-coated pectin beads: Characterization and in-vitro release of mangiferin", Food Hydrocoll., 23, 227886 (2009).

71- Y. Li, Y. Machida, T. Sannan and T. Nagai, "Preparation of chitosan microspheres containing fluorouracil using the «dry-in-oil» method and its release characteristics", STP Pharma Sci., 1, 363-8 (1991).

72- J. A. Bergisadi, "Effect of formulation variables on cis-platin loaded chitosan microsphere properties", J. Microencapsul., 16, 697-703 (1999).

73- S. Jameela and A. Jayakrishnan, "Glutaraldehyde cross-linked chitosan microspheres as a long acting biodegradable drug delivery vehicle: Studies on the $<\mathrm{i}>$ in-vitro $</ \mathrm{i}>$ release of mitoxantrone and $<\mathrm{i}>$ in-vivo $</ \mathrm{i}>$ degradation of microspheres in rat muscle", Biomaterials, 16, 769-75 (1995).

74- U. Singh and N. Udupa, "Methotrexate loaded chitosan and chitin microspheresin-vitro characterization and pharmacokinetics in mice bearing Ehrlich ascites carcinoma", J. Microencapsul., 15, 58194 (1998).

75- T. Chandy, G. H. Rao, R. F. Wilson and G. S. Das, "Development of poly (Lactic acid)/chitosan co-matrix microspheres: Controlled release of taxol-heparin for preventing restenosis", Drug Deliv., 8, 7786 (2001). 
76- I. Orienti, K. Aiedeh, E. Gianasi, V. Bertasi and V. Zecchi, "Indomethacin loaded chitosan microspheres. Correlation between the erosion process and release kinetics", J. Microencapsul., 13, 463-72 (1996).

77- Y Murata, E. Miyamoto and S. Kawashima, "Additive effect of chondroitin sulfate and chitosan on drug release from calcium-induced alginate gel beads", J. Controlled Release, 38, 101-8 (1996).

78- A. Berthold, K. Cremer and J. Kreuter, "Preparation and characterization of chitosan microspheres as drug carrier for prednisolone sodium phosphate as model for anti-inflammatory drugs", ibid., 39, 17-25 (1996).

79- I. Genta, P. Perugini, B. Conti and F. Pavanetto, "A multiple emulsion method to entrap a lipophilic compound into chitosan microspheres", Int. J. Pharm., 152, 237-46 (1997).

80- A. Sezer and J. Akbuğa, "Controlled release of piroxicam from chitosan beads", ibid., 121, 113-6 (1995).

81- I. Vural, H. Kas and A. Hincal, "Chitosantreated albumin microspheres of sulfasalazine. Part 1. Formulation and invitro release profiles", Hacettepe Univ. J. Faculty Pharm., 14, 57-65 (1994).

82- M. Bayomi, S. Al-Suwayeh, A. El-Helw and A. Mesnad, "Preparation of caseinchitosan microspheres containing diltiazem hydrochloride by an aqueous coacervation technique", Pharm. Acta. Helv., 73. 187-92. (1998)

83- J. Filipović-Grčić, M. Bećirević-Laćan, N. Skalko and I. Jalšenjak, "Chitosan microspheres of nifedipine and nifedipinecyclodextrin inclusion complexes", Int. J. Pharm., 135, 183-90 (1996).

84- L. Lim and L. Wan, "Effect of magnesium stearate on chitosan microspheres prepared by an emulsificationcoacervation technique", $\boldsymbol{J}$. Microencapsul., 15, 319-33 (1998).

85- M. Farivar, H. Kas, L. Oner and A. Hincal, "Isosorbide-5-mononitrate microspheres: Formulation and evaluation of invitro release profiles by application of factorial design", $\boldsymbol{H U} \boldsymbol{E} \boldsymbol{c z}$ Der., 13, 25-37 (1993).
86- S. Shah, R. Qaqish, V. Patel and M. Amiji, "Evaluation of the factors influencing stomach-specific delivery of antibacterial agents for Helicobacter pylori infection", J. Pharm. Pharmacol., 51, 667-72 (1999).

87- P. Giunchedi, I. Genta, B. Conti, R. Muzzarelli and U. Conte, "Preparation and characterization of ampicillin loaded methylpyrrolidinone chitosan and chitosan microspheres", Biomaterials, 19, 157-61 (1998).

88- T. W. Wong, L. W. Chan, S. B. Kho and P. W. Sia Heng, "Design of controlledrelease solid dosage forms of alginate and chitosan using microwave", J. Controlled Release, 84, 99-114 (2002).

89- H. Huang, H. Tian, X. Li and G. Zhao, "Hypoglycemic effect of chitosanmicrocapsulated insulin on the blood glucose level of streptozotocin-diabetic Wistar rats", J. Biomed. Eng., 18, 425-7, 60 (2001).

90- S. Mittal, A. Cohen and D. Maysinger, "In-vitro effects of brain derived neurotrophic factor released from microspheres", Neuroreport, 5, 2577-82 (1994).

91- S. Jameela, T. Kumary, A. Lal and A. Jayakrishnan, "Progesterone-loaded chitosan microspheres: A long acting biodegradable controlled delivery system", J. Controlled Release, 52, 17-24 (1998).

92- J. A. Ko, H. J. Park, S. J. Hwang, J. B. Park and J. S. Lee, "Preparation and characterization of chitosan microparticles intended for controlled drug delivery", Int. J. Pharm., 249, 165-74 (2002).

93- V. Kumar, S. A. Lewis, S. Mutalik, D. B. Shenoy and N. Udupa, "Biodegradable microspheres of curcumin for treatment of inflammation", Indian J. Physiol. Pharmacol., 46. 209-17 (2002).

94- Y. Nishioka, S. Kyotani, M. Okamura, M. Miyazaki, K. Okazaki, S. Ohnishi, Y. Yamamoto and K. Ito, "Release characteristics of cisplatin chitosan microspheres and effect of containing chitin", Chem. Pharm. Bull., 38, 2871-3 (1990).

95- K. Aiedehe, E. Gianasii, I. Orienti and V. Zecchi, "Chitosan microcapsules as 
controlled release systems for insulin", $\boldsymbol{J}$. Microencapsul., 14, 567-76 (1997).

96- S. Shiraishi, T. Imai and M. Otagiri, "Controlled release of indomethacin by chitosan-polyelectrolyte complex: Optimization and in-vivo/in-vitro evaluation", J. Controlled Release, 25, 217-25 (1993).

97- A. Al-Helw, A. Al-Angary, G. Mahrous and M. Al-Dardari, "Preparation and evaluation of sustained release crosslinked chitosan microspheres containing phenobarbitone", J. Microencapsul., 15, 373-82 (1998).
98- J. Akbuğa and G. Durmaz, "Preparation and evaluation of cross-linked chitosan microspheres containing furosemide", Int. J. Pharm., 111, 217-22 (1994).

99- R. Bodmeier, K. H. Oh and Y. Pramar, "Preparation and evaluation of drugcontaining chitosan beads", Drug Dev. Ind. Pharm., 15, 1475-94 (1989) 


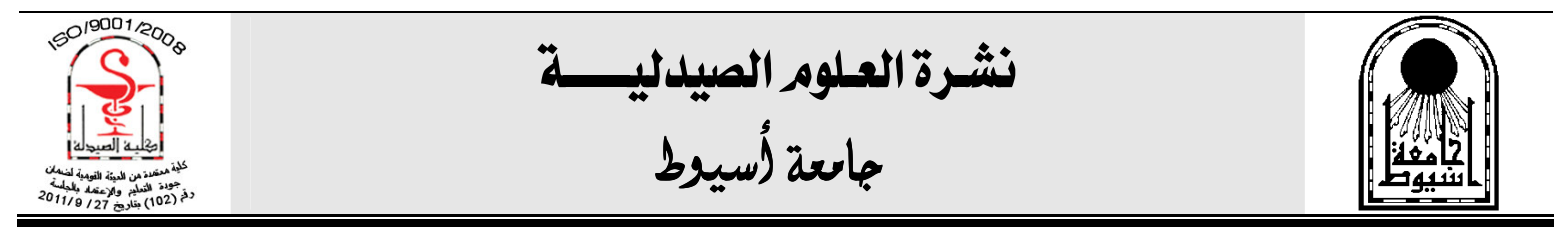

\section{كريات الكيتوزان الدقيقة كناقلات محتمله لاستهداف القولون}

هيثم حسن أحمد - أحمد مصطفى السيد - فرجانى عبد الحميد محمد - ابراهيم السيد الجبالى غريب محمد سليمان غرجان

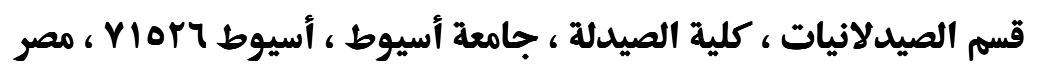

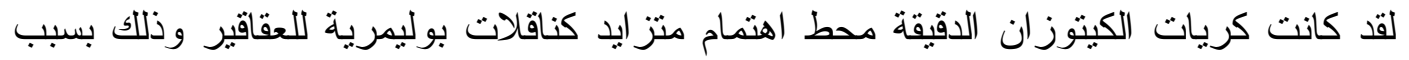

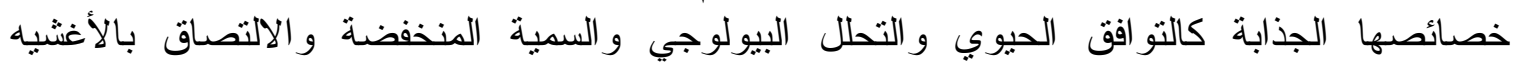

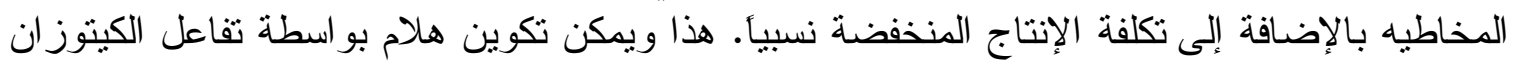

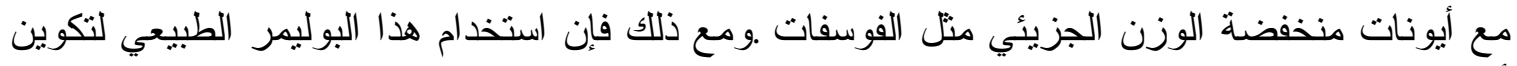

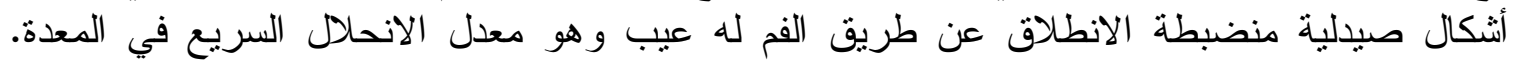

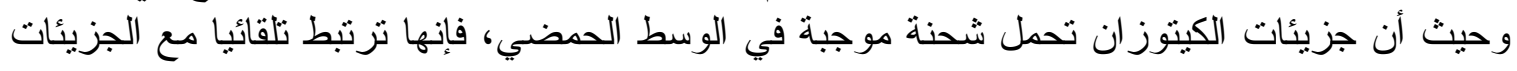

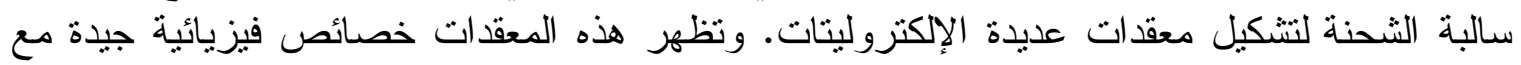

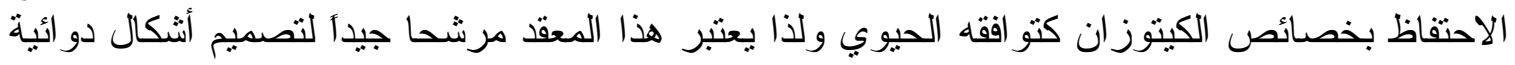

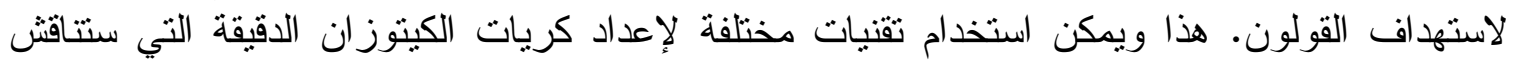
لاحقا ويشمل هذا المقال أيضا العو امل التي تؤثر على خصائص انطلاق العقاقير من هذه الكريات. 